Article

\title{
Identifying the Social Urban Spatial Structure of Vulnerability: Towards Climate Change Equity in Bogotá
}

\author{
Vasco Barbosa ${ }^{1,2,3, *}$ and Mónica Marcela Suárez Pradilla ${ }^{4}$ \\ ${ }^{1}$ Faculty of Engineering, Universidad de La Sabana, Colombia; E-Mail: vasco.barbosa@unisabana.edu.co \\ 2 proMetheus, Polytechnic Institute of Viana do Castelo, Portugal \\ 3 Department of Sociology, University of Johannesburg, South Africa \\ ${ }^{4}$ Department of Civil Engineering, Colombian School of Engineering Julio Garavito, Colombia; \\ E-Mail: monica.suarez@escuelaing.edu.co \\ * Corresponding author
}

Submitted: 27 June 2021 | Accepted: 15 September 2021 | Published: 16 December 2021

\begin{abstract}
The constant modification of land use, economic instability, environmental factors, and social behaviour changes among the inhabitants of big cities characterize current urbanism. In Colombia, land-use planning processes supported by geographical information systems are a recent phenomenon and the legal instruments of spatial planning are inadequate in most municipalities. Moreover, socio-spatial equity represents a challenge for Latin American cities in which there is increasing awareness of the role that spatial planning plays. Consequently, the question arises as to how the urban spatial structure and organization contribute to an inclusive and equitable socio-spatial evolution, considering climate change impacts. The case study analysed in this article focuses upon the northern limits of the city of Bogotá. Therefore, this research aims to define the ideal balance of urban land-use distribution between social stratum classification and the vulnerability of the communities seeking to better adapt to climate change. We propose a methodological approach of analysing spatial syntax and the (social) intensity of activities and infrastructure, which enables us to characterize the urban structure itself and identify vulnerable urban instances. As a result, we find that the urban network with low values presents spatial unpredictability in its pattern, constraining equitable development based on the urban morphology of the city. This research allows us to conclude that the degree of vulnerability encountered by the social urban spatial structure is higher in expansion areas than in central areas of the city.
\end{abstract}

\section{Keywords}

Bogotá; climate change; social space; spatial vulnerability; urban morphology; urban structure

\section{Issue}

This article is part of the issue "Planning for the Local Impacts of Climate Change: Nobody Left Behind?" edited by Mark Seasons (University of Waterloo, Canada).

(C) 2021 by the authors; licensee Cogitatio (Lisbon, Portugal). This article is licensed under a Creative Commons Attribution 4.0 International License (CC BY).

\section{Introduction}

Urban metropolises and peripheral areas have experienced pressures and changes in land-use, infrastructure, and loss of agricultural land (Shen et al., 2019), continuing prioritization of short-term growth as opposed to alternative approaches to sustainable urban growth to compact forms (Ahern, 1995; Menzori et al., 2021), or through strategic spatial planning (Hersperger et al., 2018). These peripheral areas of urban sprawl have witnessed the greatest transformation dynamics (Aguilar, 2008; Guo et al., 2020). The peripheral cities (in the context of metropolises, neighbouring communities) usually have a propensity for lower economic cost of land-use, regardless of their future urban functions. These characteristics can be related to elements that support the 
spatial build-up of urban space, namely accessibility and connectivity through the mobility axes that make up the urban network (Jayasinghe et al., 2019). Furthermore, the urban structure, defined as the urban morphology that seeks to identify how the city is organized and its alterations, acquires an important role (Benita \& Piliouras, 2020; Ouyang et al., 2021).

The growth of the world's urban population has increased the effects of climate change due to high urbanization and agglomeration. Consequently, urban centres suffer long-term and far-reaching effects, not only on their immediate boundaries, but also on the entire region in which they are located (While \& Whitehead, 2013). Depending upon the socio-spatial structure of cities, the effects of physical processes (urbanization, urban planning, infrastructure provision, or transport), and of human processes (lifestyle choices and consumption patterns) lead to vulnerability (Otto et al., 2017). Communities will always face natural hazards, but today's disasters are generated by human activities, poor land-use planning, lack of environmental management, and regulatory mechanisms that increase risk and exacerbate impacts (Birkmann et al., 2010). Moreover, urban planning is relevant as an instrument of urban development in its various dimensions, therefore municipalities need to draw up municipal land-use plans which are as equitable as possible. An understanding of urban morphology facilitates the projection of future growth on a municipal scale (Ariza-Villaverde et al., 2013). The urban informality partially characterizes the evolution of spatial structures in Latin America, such as in the case of natural hazards, that is, accidents that render some populations and zones of cities subject to greater human vulnerability (Gonzales \& Magnaye, 2017; Unceta et al., 2020).

Thus, this manuscript tackles the theme of urban vulnerability according to a new spatial dimension, that is, through urban morphology and street network, against the background of climate change. It is desirable that this element could be introduced into the municipal urban planning discourse in future because the climate emergency and its impacts are real (Yan et al., 2021). Basu and Das (2021) highlight the need to integrate the environment into urban planning. Are public policymakers involved in urban planning allocating areas or land uses appropriately and equitably? Considering the reality of climate change and its direct impact on populations, how is urban planning affected?

\subsection{Review Literature}

Social vulnerability and equity in the context of climate change are important because some populations may have less capacity to prepare for, respond to, and recover from climate-related hazards and impacts. These peripheral populations may be disproportionately affected by climate change (Gencer, 2013). The Intergovernmental Panel on Climate Change $(2007$, p. 6) describes vulner- ability as "the degree to which a system is susceptible to, or unable to cope with, the adverse effects of climate change, including variability and extremes." Areas of urban expansion are territorial units that serve urban management and are based on a plot structure. They are also urban zones that allow for urban development with socio-economic functionality (Dadashpoor \& Ahani, 2021; Weldearegay et al., 2021).

In the case study of the municipality of Chía, peripheral to the capital of Colombia, Bogotá, these areas of expansion are located along or close to two existing rivers, among other characteristics of the city. These expansion areas are defined in Bogotá's municipal planning legal instrument, called the Plan de Ordenamiento Territorial (POT). These expansion areas are in urban zones with a high incidence of poverty as measured by the Multidimensional Poverty Index of the Colombian statistics office (National Administrative Department of Statistics of Colombia [DANE], 2021a). This urban context, faced with social and spatial dimensions and overlapping spatial attributes, identifies a potential risk to urban development. Moreover, sustainable and equitable development is sought with a focus on urban resilience (Du et al., 2020). There is a high risk of spatial vulnerability, according to the urban structure that defines the city, and which features the growth of its urban area. A real urban problem of considerable scale arises when in the future a major natural incident occurs in the context of climate change, which is framed by the constant urban changes that cities have experienced (Hill, 2016). Moreover, urban road mobility is a major driver of urban growth, so that the importance of better identifying the characteristics of the road structure is even more relevant to urban planning.

In a more critical vein, there are numerous studies on urban sprawl (Jaeger et al., 2010). Alfasi et al. (2012) evaluate the current performance of municipal land-use plans, whereas Inostroza et al. (2013) and Madlener and Sunak (2011) monitor growth patterns, effects of urbanization, and identify spatial metrics to characterize urban development without integrating urban mobility infrastructure. Several attempts have been made to contextualize the relationship between urban vulnerability and climate change. However, several approaches complement each other. Most of these relate to the environment, natural hazards, political economy, and ecological resilience (Bulkeley \& Tuts, 2013). Environmental studies conceive urban vulnerability as the result of, or exposure to, climate hazards affecting the population, infrastructure, and urban activities in general (Eakin \& Luers, 2006; Romero Lankao \& Qin, 2011). Finally, studies focusing upon urban resilience seek to identify short or long-term coping mechanisms to deal with these effects (Zhang et al., 2020). These vulnerability challenges highlight the need for cities to rethink how people are protected, how infrastructure investments are prioritized, and how to include climate in cities' long-term growth and development plans (Rani et al., 2020). 
More recent studies analyse urban expansion and population growth, patterns of land-use-land-cover changes, or the impacts spatial growth generates in relation to socio-spatial vulnerability (Barros et al., 2018; de Espindola et al., 2017; Matsa et al., 2021; Padeiro, 2016). However, these studies do not introduce urban mobility as a configuring element of the urban space. Similar results occur when authors develop a system of indicators to evaluate the level of integration of urbanization (Gan et al., 2020). Conversely, studies regarding node-place analysis as a tool to define the characteristics of transport nodes in terms of transport quality and intensity and diversity of land-use of the surrounding areas are widely developed (Jayasinghe et al., 2019; X. Liu et al., 2021; Nigro et al., 2019). Urban vulnerability is currently addressed from the perspective of ecosystem assessment or urban conversion zones to improve the management of specific areas such as coastal regions (Bianco \& García-Ayllón, 2021; Ghosh \& Das, 2019; Li et al., 2016), without an analysis of the urban morphology in relation to the mobility network, such as infrastructure axes and urban development. These studies essentially focus upon the environment and do not contain the in-depth socio-spatial dimension as an analytical component.

Furthermore, climate change studies correlated with urban planning have been intensively developed in recent years, from urban climate change adaptation and mitigation measures (Santos et al., 2021; Sharifi, 2021) to evaluations of the impacts of urban growth and urbanization processes (Ahmed et al., 2020; Lee \& Kim, 2021; Salimi \& Al-Ghamdi, 2020), climate governance (Giordano et al., 2020; M. Liu \& Lo, 2021), assessments of climate change risk at an urban scale (Ye et al., 2021), and public health (de Oliveira Lemos et al., 2021).

Nevertheless, these studies highlight the common shortcoming of not integrating spatial vulnerability and urban morphology, as they do not enable a global understanding of the social behaviour of cities and how urban expansion areas can contribute to the mitigation of urban vulnerability. Thus, one of the challenges of the research is to spatialize the interrelation of these aspects, namely urban expansion areas, spatial vulnerability, and street network to support the perception of urban vulnerability by land-use planners against the background of climate change. This study focuses upon the following research questions: Considering climate change impacts, how does urban spatial structure and organization contribute to an inclusive and equitable socio-spatial evolution? Does the understanding of the articulation of these urban factors and vulnerability play an essential role in achieving an urban planning that allows for social equity?

The present study seeks to formulate a new approach to the spatial analysis of the urban form (urban morphology) by integrating climate change into the analytical framework. The possibility of implementing the practice and insertion of climate change in the legal instruments of municipal planning, in this case the POT, as an exercise of the urban planning field is found to be an advantage. Against this background, space syntax, which observes the social logic of space in cities through natural movement theory and behaviour, appears to be an appropriate method (Hillier \& Hanson, 1989; Penn, 2003; Yamu et al., 2021). Space syntax also relates to street network through the analysis of a specific set of parameters explored further below. This article proposes a new approach that makes two contributions: (a) to mitigate the degree of socio-spatial vulnerability of the citizens, and (b) to redirect new strategies of definition, delimitation, and location of the city's expansion areas in the context of urban informality. It is necessary to understand and evaluate the location of urban expansion areas to realize new possibilities of ensuring urban development without exacerbating the citizens' degree of vulnerability. In the current context of urban resilience, it is desirable that the level of vulnerability is still considered reversible. Against this background, the main objective of this article is to define the ideal balance of urban sprawl distribution between social stratum classification and the troubled prospect of communities obtaining better adaptation to climate change, and thus to determine social urban spatial structure vulnerability. The article is organized as follows: Section 2 describes the study area and the social-spatial units considered in the research. The results and discussions are presented in Section 3, followed by Section 4 summarizing the key findings as main conclusions.

\section{Methodology}

\subsection{Study Area}

Colombia has the following instruments to manage climate change at municipal, departmental, and national level: the nationally determined contributions, the national climate change policy, integrated sectoral and territorial climate change management plans, the development plans of territorial entities and land-use plans and national communications, national greenhouse gas inventories, biennial update reports, and others reports. This article studies the urban area of the municipality of Chía (Figure 1). The case study is located between the northern limit of the city of Bogotá and the municipalities of Chía and Cota that are part of the Sabana Centro region. This area is characterized by a municipal border location and spatial pressure due to its proximity to the metropolis (Jimenez Aguilar \& Thoene, 2021). Due to this spatial context, this case study allows for a comparison with other metropolitan cities, their interrelationships, and spatial dynamics. Chía is a municipality in the metropolitan area of Bogotá and is located on the northern edge of the city. It is part of the department of Cundinamarca and represents $1.2 \%$ of the Colombia's production and $0.97 \%$ of the national population (Cámara de Comercio de Bogotá, 2015). It is also part of the Sabana Centro province, with 10 municipalities 

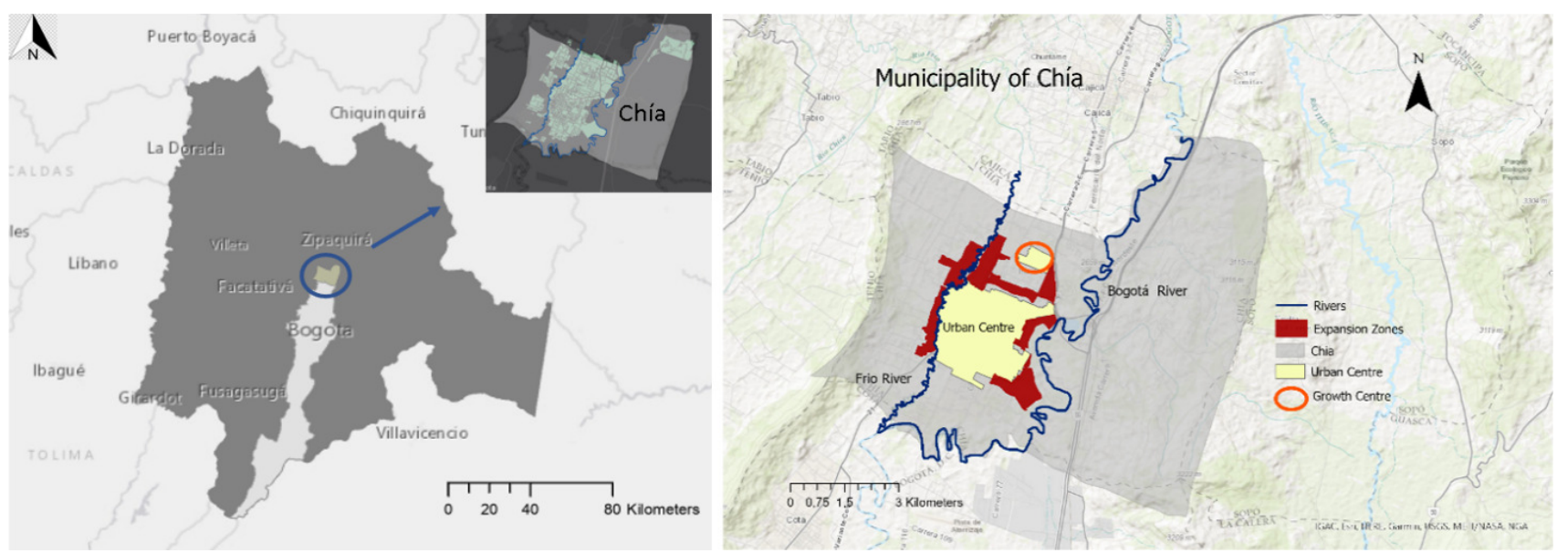

Figure 1. Location of the municipality of Chía (left) and the map of the city (right).

located in the area bordering the north of Bogotá. Chía has experienced an important population evolution in recent years due to large real estate developments and an increase in economic activity, which have caused territorial changes and impacted its urban growth. The city's development model is based on the fact that it is considered a peripheral municipality. It seeks to focus its development mainly on the occupation of land use with a residential function to attract more population from the metropolis. The expansion areas and their allocated uses are mostly for residential construction. It has a population of 105,509 inhabitants in the urban area and 26,672 inhabitants in the populated centres according to the 2018 census of the DANE and an area of 7,900 ha, of which 630.17 ha (7.83\%) are urban land; 299.84 ha $(3.73 \%)$ are urban expansion land, and $7,114.90$ ha (88.44\%) are rural land according to the 2016 land-use plan (Consejo Municipal de Chía, 2016). One of the most important effects of climate change in the municipality of Chía is related to flooding. The urban area of the municipality and two expansion zones are located between the Frío and Bogotá rivers. Changes in land use, as well as dispersed real estate growth and economic activities developed in buffer zones of the river, are one of the main causes of vulnerability and flood risks in the municipality. Particularly, the floods of 2010 and 2011 showed the importance of assessing the vulnerability of the inhabitants located near the rivers (Duran Giraldo \& Suárez Jaraba, 2013).

The new metropolitan processes of urban sprawl or conurbation, for example, have resulted in the movement of middle- and high-income population from the city of Bogotá to the municipalities in its immediate urban surroundings in search of a better quality of life. This has generated changes in the territory, in the transformation of residential areas, and in the way of life of local inhabitants. Particularly in Chía, there are processes of residential segregation, especially in the sectors where urbanization is isolated from the traditional centre, or in the areas of around the Frío and Bogotá rivers (Osorio Ardila, 2012). This process presents an important challenge in terms of habitat, economic development, and environmental sustainability, and implies the modification of territorial and urban planning processes in the short, medium, and long term (Contreras Ortíz, 2017). The area occupied by the territory and population of Chía is affected by the strong functional relationship with Bogotá, intensifying its daily mobility flows either for work or study and generating urban relations of a metropolitan nature. Migration to Chía has led to a dispersed socio-spatial phenomenon, especially in rural areas, and an imbalance in the development of the services and facilities needed to serve residential use as there is no structural articulation (Cámara de Comercio de Bogotá \& Alcaldía de Bogotá, 2015).

\subsection{Conceptual Approach to Social Urban Spatial Structure Vulnerability}

A framework is required to obtain a conceptual understanding of social urban spatial structure vulnerability (Figure 2). The conceptual proposal addresses urban planning that responds to the emerging needs of climate change adaptation. Thus, the social sphere is considered as the main vector of integration. Hence, we spatialized the various social data with the urban morphology by means of geographic information systems and space syntax. The vulnerability of the sociospatial structure is projected as follows. On the social side, three sub-themes have been defined which are associated with quantitative data. However, the subthemes include the socio-qualitative dimension. Thus, the data relationship is: urban communities have population density data; urban vulnerability factors integrate Multidimensional Poverty Index data, the demographic vulnerability index, and vulnerability by age group; and social distribution integrates social stratum type data. On the spatial structure side, a single quantitative data type is presented. The data relationship can be expressed as follows: The area of urban expansion includes the data of the city. Therefore, the socio-spatial structure intersects with the urban morphology to allow an integrated 


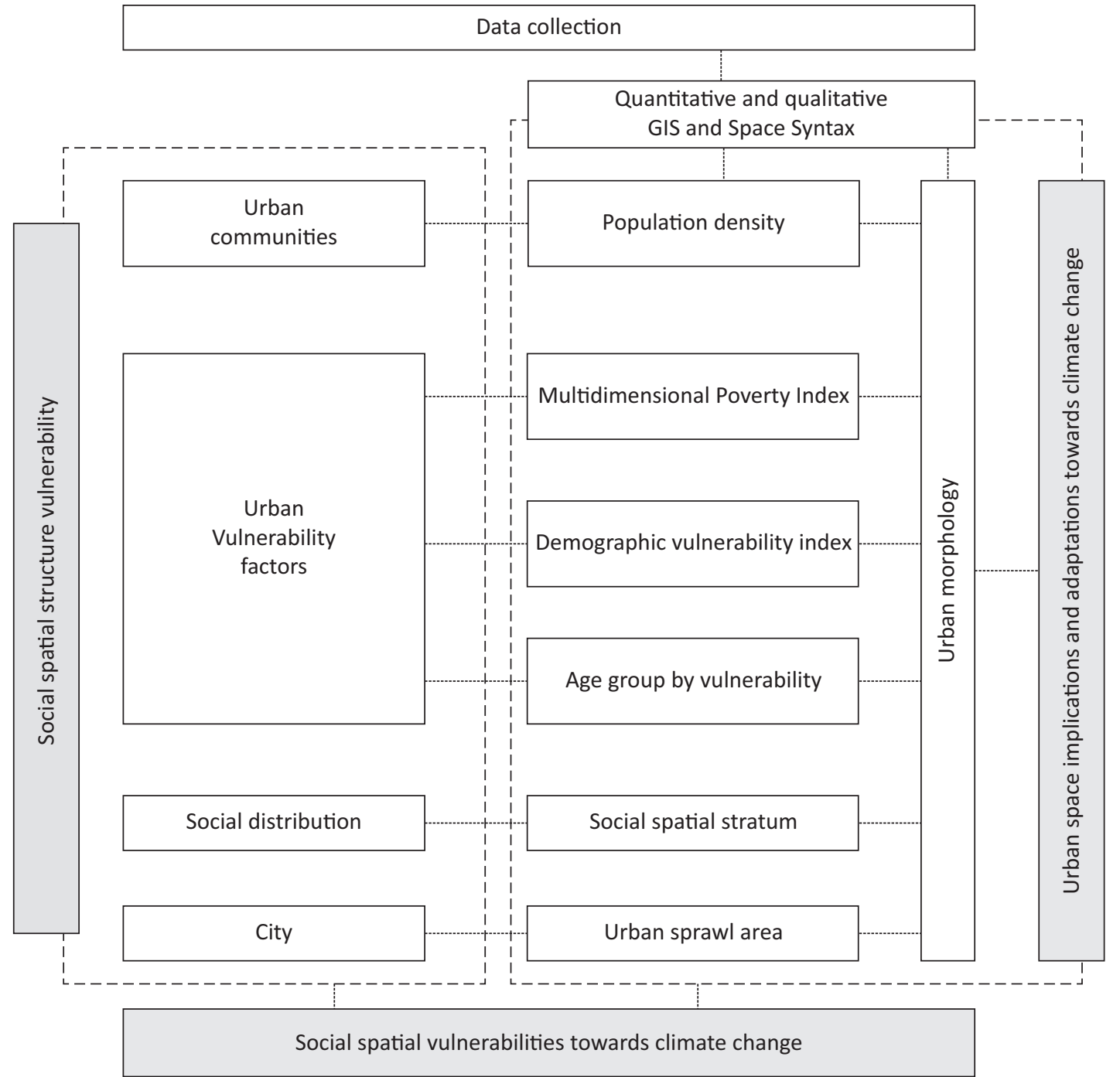

Figure 2. Conceptual framework of social urban spatial structure vulnerability.

reading of the socio-spatial characteristics of the urban space. The development of this conceptual approach rests on two aspects of the data typology that enables us on the one hand to locate and spatialize the social vulnerabilities to climate change, and on the other to seek to understand the implications of, and necessary adaptations in, the expansion areas against the background of climate change.

\subsection{Social and Urban Data}

\subsubsection{Social Dimension}

In this research, a diagnosis of the municipality of Chía has been carried out at the cadastral block level using official information from the 2018 population census (DANE) to show how the territory of the municipality behaves with respect to social vulnerability. Vulnerability has different meanings that are approached using different theories and epistemologies either in a general way or in its different modalities (natu- ral, demographic, social, socio-demographic, or others). Vulnerability encompasses three different dimensions: risks (events), inability to respond to such risks, and the inability to adapt to the new situation generated by such risks (Rodríguez Domenech, 2016). In this article we seek to emphasize some social aspects of vulnerability related to demography, which are encapsulated in the Multidimensional Poverty Index. To give a socioeconomic focus to the analysis, socio-economic strata are included. The following briefly explains how these indices are defined and what the social strata mean in the context of Colombia.

\subsubsection{Multidimensional Poverty Index}

This indicator is used by the Colombian government to assess poverty. It has five dimensions and involves 15 variables: educational conditions; children and youth conditions; work; health; and housing conditions and public services. According to the 2018 census, as a department Cundinamarca has the second lowest 
Multidimensional Poverty Index value in the country (DANE, 2021a). At the municipal level, Chía has a Multidimensional Poverty Index of $4.7 \%$, which places it among the municipalities with the lowest poverty rate in the country (a municipality is considered to have a high multidimensional poverty rate if the index has a value greater than or equal to $33 \%$ ). This index is used in this research to show the areas of the municipality that require greater attention in urban planning processes due to the vulnerability of inhabitants in different dimensions (DANE, 2021b; Department of National Planning, 2017).

\subsubsection{Demographic Vulnerability Index}

The impact of natural hazards is not the same for all people and not all people have the same capacity to adapt; thus, it is necessary to anticipate these events (Brie, 2019). This leads us to define social vulnerability as the set of characteristics that help communities to adapt and become resilient, which includes demographic vulnerability considering demographic characteristics and population dynamics according to age distribution (Hogan \& Marandola, 2005). Other elements can be considered, but in this research the socio-demographic vulnerability index identifies the density of population over 60 years old living in the municipality that harbours risks associated with ageing and monetary poverty that need to be included within planning policies.

\subsubsection{Socio-Economic Stratification in Colombia}

Socio-economic stratification in Colombia is an approximate representation of the income level of citizens and is meant to provide a degree of equity in the system of residential public utilities that inhabitants pay. In other words, socio-economic stratification facilitates the differentiated charging of residential public services, obliging families with greater economic capacity to subsidize those with fewer resources (DANE, 2021a; Guevara \& Shields, 2019). We subsequently studied urban elements according to the hotspot technique (N. Liu \& Morawska, 2020; Qi et al., 2020), a frame with a set of spatial variables referring to space syntax. These variables are explained in detail below.

\subsubsection{Urban Morphology}

We propose a methodology of spatial syntax and an analysis of the (social) intensity of activities and infrastructure usage, which enables characterization of the urban structure itself and at the same time identify vulnerable urban zones. Space syntax sprang from the observation that space is the common ground of physical and social cities. In syntactical terms, spatial configuration means relations between spaces which consider other relations, hence in effect relations between all the various spaces of a system (Remali et al., 2015). Axial analysis is one of the fundamental components of space syntax. Proponents of space syntax suggest that it picks up the qualities of configurational relationships between spaces not illuminated by other representations (Turner, 2007). As a first step, an axial map is built over all the urban accessibility routes in the area under study, in this case Chía's urban area (Figure 3).

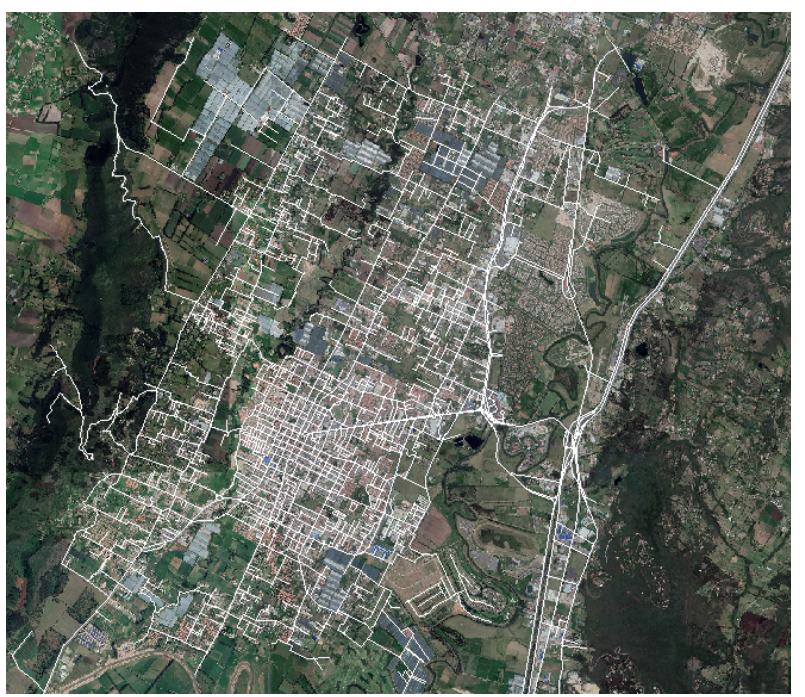

Figure 3. Support for and institutionalization of direct democracy. Source: Geissel (2016).

Space syntax analysis reveals knowledge of the connectivity, choice, control, entropy, and integration parameters required to understand the global structure of the urban network ( $R$ Core Team, 2021). One of the strengths of space syntax is its parsimony as it only considers the geometry of the street pattern without any other contents (land-use, aesthetics, transport, etc.), allowing for fast, cheap, and objective analysis (D'Acci, 2019). Attending to the special context of the city under scrutiny, these were the parameters considered most appropriate if we were to formulate questions on the area of expansion and the vulnerability of the urban structure. Subsequently, the concepts of the space syntax parameters under analysis are explained. Connectivity is defined in space syntax theory as the number of nodes that connect directly to a given node in the dual graph $G$. Space syntax considers the accessibility of a space as a key determinant of its spatial interaction and its analysis is based on an implicit graphtheoretic view of the dual graph. In graph theory, the space syntax connectivity (Equation 1) of a node is called the 'node degree':

$$
\text { Connectivity }(i)=\operatorname{deg}(i)=\sum_{j=1}^{N}\left(\mathbf{A}_{(\mathbf{S}}\right)_{i j}
$$

The calculation behind choice (or between-ness) $C$, of an axial line $i$ is derived by the following equation (Equation 2), where $g_{j k}(i)$ is the number of shortest paths between lines $j$ and $k$ containing $i$, and $g_{j k}$ is the number of all shortest paths between $j$ and $k$ as: 


$$
\text { Choice } C_{i}=\sum_{j} \sum_{k} \frac{g_{j k}(i)}{g_{j k}(j<k)}
$$

Control value $(C V)$ is another local measure used in space syntax theory. It evaluates the degree to which a space controls access to its immediate neighbours considering the number of alternative connections that each of these neighbours has. The $C V$ is determined according to the following equation (Equation 3 ), where the diagonal matrix is $D=\operatorname{diag}(\operatorname{deg}(1), \operatorname{deg}(2), \ldots, \operatorname{deg}(N))$ :

$$
C V(i)=\sum_{i \sim j} \frac{1}{\operatorname{deg}(j)}=\sum_{j=1}^{N}\left(\mathbf{A}_{\mathbf{O S}} \mathbf{D}^{-1}\right)_{i j}
$$

The estimation of entropy for spatial systems is based on the frequency distribution of the point depths (Turner, 2007). The point depth entropy of a location, si, is expressed by utilizing Shannon's formula of uncertainty as shown in Equation 4, where dmax is the maximum depth from [vertex] $v i$ and $P d$ is the frequency of point depth $d$ from the [vertex]:

$$
\text { si } \sum_{d=1}^{d \max }-P d \log 2 P d
$$

The integration $(I)$ of an axial line $i$ is a function of its depth related to all the other axial lines (how many steps are distant from all others). The latter (Equation 5) is calculated by assigning a depth value to each space according to how many spaces it is away from the original space, summing these values and dividing by the number of spaces in the system less one, where $n$ is the number of axial lines in the urban street area considered, $d_{i j}$ is the shortest distance (least number of steps) between two axial lines $i$ and $j$ (D'Acci, 2019):

$$
\text { Integration } I_{i}=\frac{2\left(n\left(\log _{2}\left(\frac{n+2}{3}\right)-1\right)+1\right) /(n-1)(n-2)}{2\left(\left(\frac{\sum_{j=1}^{n} d_{i j}}{n-1}\right)-1\right) /(n-2)}
$$

At the end of the calculation of the axial measures explained above, the accessibility value is determined by calculating the correlation between the choice measures and overall integration (Dou \& Zhan, 2011; Morales et al., 2019). This calculation is relevant since it enables identification of the degree or accessibility value of an urban system, thus furnishing an understanding of spatial organization as urban mobility.

\section{Results and Discussion}

Most of the population of Chía occupies the urban area, although the villages of the western zone such as Fagua, Tíquiza, and Fonquetá, and the villages of the central zone such as Bojacá and Samaria, have sectors of high population density (Figure 4a). These population density areas are very close to the expansion zones defined in the POT of 2016. Each of these instances of growth has particular characteristics. In the western area there are still several agricultural and vacant land plots and natural environment, whereas the urbanized area is located on the river Frío. The population density of the central zone corresponds to a process of urban consolidation. In this sector there are also flower farms on both banks of the river and other plots are used for rural housing. To analyse the levels of multidimensional poverty (Figure 4b), an incremental spatial autocorrelation analysis was used, which shows that the sectors located in the northern part of the municipality in the villages of Fagua and Tíquiza between the river Frío and the Fagua-Cajicá road and the sector located in the village of Bojacá that borders the river Frío and Samaria village are those that present a concentration of people with the highest Multidimensional Poverty Index. On the other hand, it is observed that the urban centre is the least vulnerable. Similar to the previous autocorrelation analysis, in this research the demographic vulnerability corresponds to people over 60 years old. The results show that the traditional urban sector is the one that presents a positive concentration of people over 60 , which indicates that this zone is vulnerable at a demographic level, like the Yerbabuena district. The sectors of Fagua, Tíquiza, and Bojacá are not vulnerable.

Social vulnerability (Figure $4 d$ ) in this research refers to a combination of demographic variables, comorbidities of the population, and population density. Social vulnerability is analysed at the block level and classified into five levels of vulnerability: low, medium-low, medium, medium-high, and high. The highest levels of vulnerability in the municipality of Chía are located in the urban centre and especially in some sectors of the different hamlets. Finally, in terms of stratification (Figure 4e), in the Western zone, specifically in the villages of Piedra and Fonquetá, there is a higher percentage of strata 1 and 2, which are the lowest strata. The villages of Bojacá, Yerbabuena, and La Balsa have the highest percentage of strata 5 and 6 . In the traditional urban area, approximately $0.8 \%$ of the properties are classified as stratum 1 , with a predominance of strata 2 and 3 . Analyses were conducted at the census block level; the data used for the social vulnerability analysis are up to date as of June 2021. The Multidimensional Poverty Index and demographic vulnerability analysis was conducted using data from the 2018 census (DANE, 2021a). The social strata were obtained from the cadastral base (DANE, 2021a).

Concerning the urban morphology data, different colours mark different values as the results (Figure 5). The Connectivity axis map (Figure 4a) shows spatial results that are considered limiting. For all maps, the results are represented in the legend by a colour scale corresponding to red (high values) and blue (low values). The central and least central axes of the urban area present higher values of connectivity, and the surrounding areas lower values, that is, with minimum values. They coincide with urban areas of expansion, that is, these are remote areas with difficult connections to 

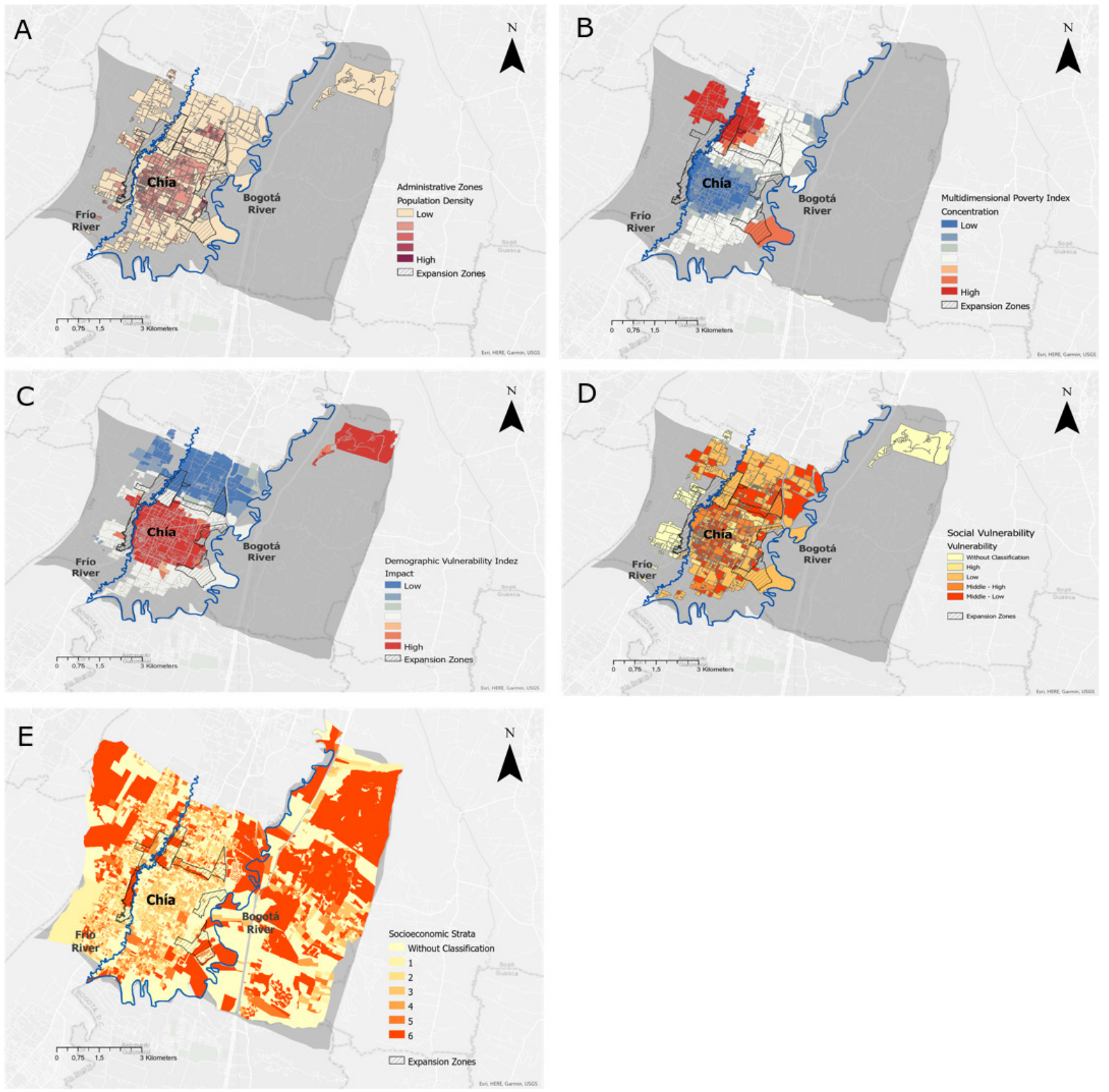

Figure 4. Social urban spatial structure vulnerability: (a) population density, (b) Multidimensional Poverty Index, (c) demographic vulnerability index, (d) social vulnerability, and (e) socioeconomic stratum.

the city. It is in these areas that the most vulnerable groups are located. Therefore, the results enable us to assess that the urban structure is somewhat ineffective with respect to the interconnecting road between the proposed expansion areas and the main road axis of the city located in the central zone. From the axial map referring to the Choice variable (Figure $4 \mathrm{~b}$ ), one of the results obtained is that a road located in the north-west, along the river Frío and across the expansion area, presents a medium-high value. This means a medium-high probability that this road will be chosen as a route, increasing the pressure of urban traffic on an area of the city which is environmentally sensitive owing to its proximity to the rivers Frío and Bogotá where a low social stratum is located. The central zone displays two parallel roads and a diagonal road with the highest values compared to the rest of the urban system. This suggests a concentration of urban mobility that is not efficient in terms of urban planning. Regarding the axial map Control (Figure 4c), the main result that can be identified is that most values are less than 1 , that is, it is possible to identify a high number of axes in blue. The degree of choice among immediate neighbouring axes is low. This means that there are several possibilities of road interconnection at short range, which gives a certain diffusion of the urban network. This same diffusion coincides with the expansion 

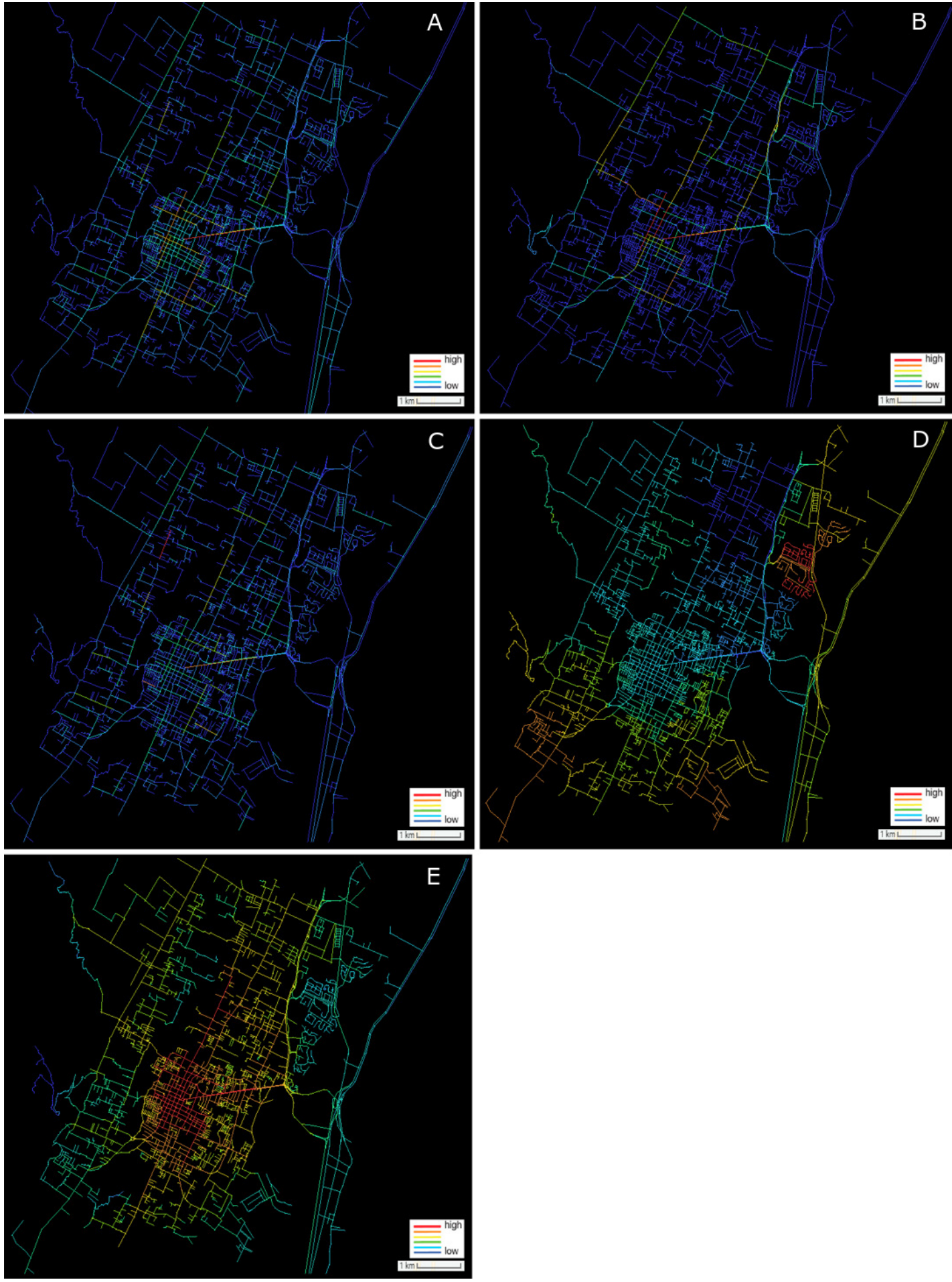

Figure 5. Axial maps of Chía's urban space with the spatial variables: (a) connectivity, (b) choice, (c) control, (d) entropy, and $(\mathrm{e})$ integration global $(\mathrm{HH})$.

areas and on the north-west side with the proximity of the river as a natural element. This context allows the identification of an urban risk zone as the spatial vulnerability. The axial Entropy map (Figure 4d) reveals a global result of low values, suggesting a reading of the city as spatial disorganization, or unorganized spatial pattern, considering that only one urban area having high values is located to the north-east. The rest of the city area displays opposite values. Moreover, the two expansion areas are located towards the west and north. From the result, we can observe that the urban network with low values presents spatial unpredictability in its pattern, constraining an equitable development based on the urban morphology of the city. The result for the variable Integration (Figure 4e) highlights the central area, that is, the old part of the city, and the diagonal axis with 
higher integration values. The north-east area, where the river and one of the most socially vulnerable zones are located, displays low integration values in the global system of urban axes. This urban structure lacks homogeneity in its spatial pattern. These areas with low values are located alongside one of the largest expansion areas adjacent to the river, and as such are potential areas of risk in urban management.

In the connectivity mode variable (Table 1 ), the average value is 2.00 , which means that the urban area has little effective connectivity in relation to the spatial pattern of urban axes that allow road accessibility. This is visible between the minimum value of 1.00 and the maximum value of 20.00 . The coefficient of variation is greater than $50 \%$, which indicates asymmetry in the structure of urban axes. Regarding choice, the coefficient of variance is high at 242.41. This value refers to the whole urban system and indicates that there are few roads that are apt to be elected as preferred road infrastructure. The overall integration values $\mathrm{HH}$ are low. The coefficient of variance is less than $50 \%$, namely 25.37 . Therefore, the result indicates integration based on structural urban axes that are not very attractive or accommodate urban mobility.

The data of the connectivity variable as a function of the control variable seem to increase proportionally
(Figure 6). This means that there is a spatial structure of roads with connectivity values such as control, when compared to the global area. The variance values enable us to gauge a numerical approximation, thus equilibrium in these variables, when referring to the behaviour of connections between urban axes. As a function of integration, the entropy variable shows a negative correlation, that is, a spatial pattern of global integration of urban axes opposed to local integration in central and northern areas of Chía. As a function of connectivity, all variables concentrate their values. The figure shows that when relating the integration variables to connectivity the integration data is concentrated in the range 0 and 10.

The accessibility of the overall urban structure (Figure 7), calculated using the correlation between the variables choice and integration $(\mathrm{HH})$, obtains the value of $R=0.024$. This is a low value in the range 0 and 1 . This result shows that urban accessibility presents difficulties owing to the few alternative routes that Chía possesses, which can predict a structure of urban axes that is not effective. This result can support urban planning decision-making for the specific issue of road mobility.

The discussion must be framed by the attempt to interpret the data of set variables analysed within the

Table 1. Descriptive statistic of connectivity, choice, control, entropy, and integration global HH.

\begin{tabular}{lcrrrr}
\hline Variable & Connectivity & \multicolumn{1}{c}{ Choice } & Control & Entropy & Integration [HH] \\
\hline Mean & 2.46 & $59,660.71$ & 1.00 & 5.14 & 0.42 \\
Median & 2.00 & $10,456.00$ & 0.83 & 5.12 & 0.42 \\
Mode & 2.00 & 0.00 & 1.00 & 5.10 & 0.41 \\
Standard deviation & 1.65 & $144,621.50$ & 0.83 & 0.13 & 0.11 \\
Variance & 2.73 & $20,915,378,716.50$ & 0.68 & 0.02 & 0.01 \\
Skewness & 3.48 & 4.24 & 3.58 & 0.38 & -0.24 \\
Minimum & 1.00 & 0.00 & 0.05 & 4.89 & 0.12 \\
Maximum & 20.00 & $1,273,556.00$ & 10.67 & 5.45 & 0.65 \\
Coeficient of variation (\%) & 67.13 & 242.41 & 82.60 & 2.56 & 25.37 \\
\hline
\end{tabular}

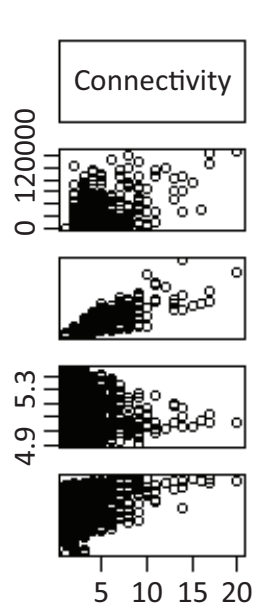

0600000

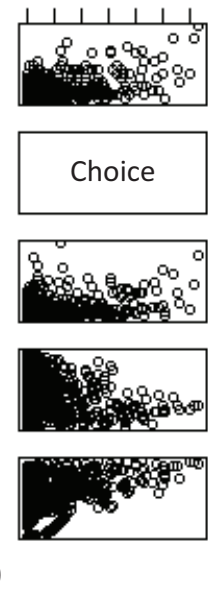

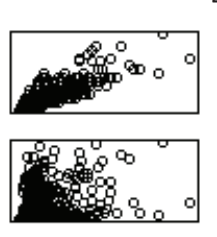

$\begin{array}{lll}4.9 & 5.1 & 5.3\end{array}$

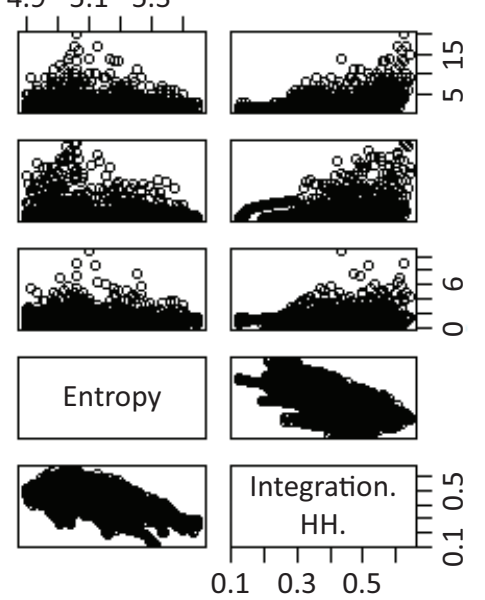

Figure 6. Plot descriptive statistic of urban space variables. 


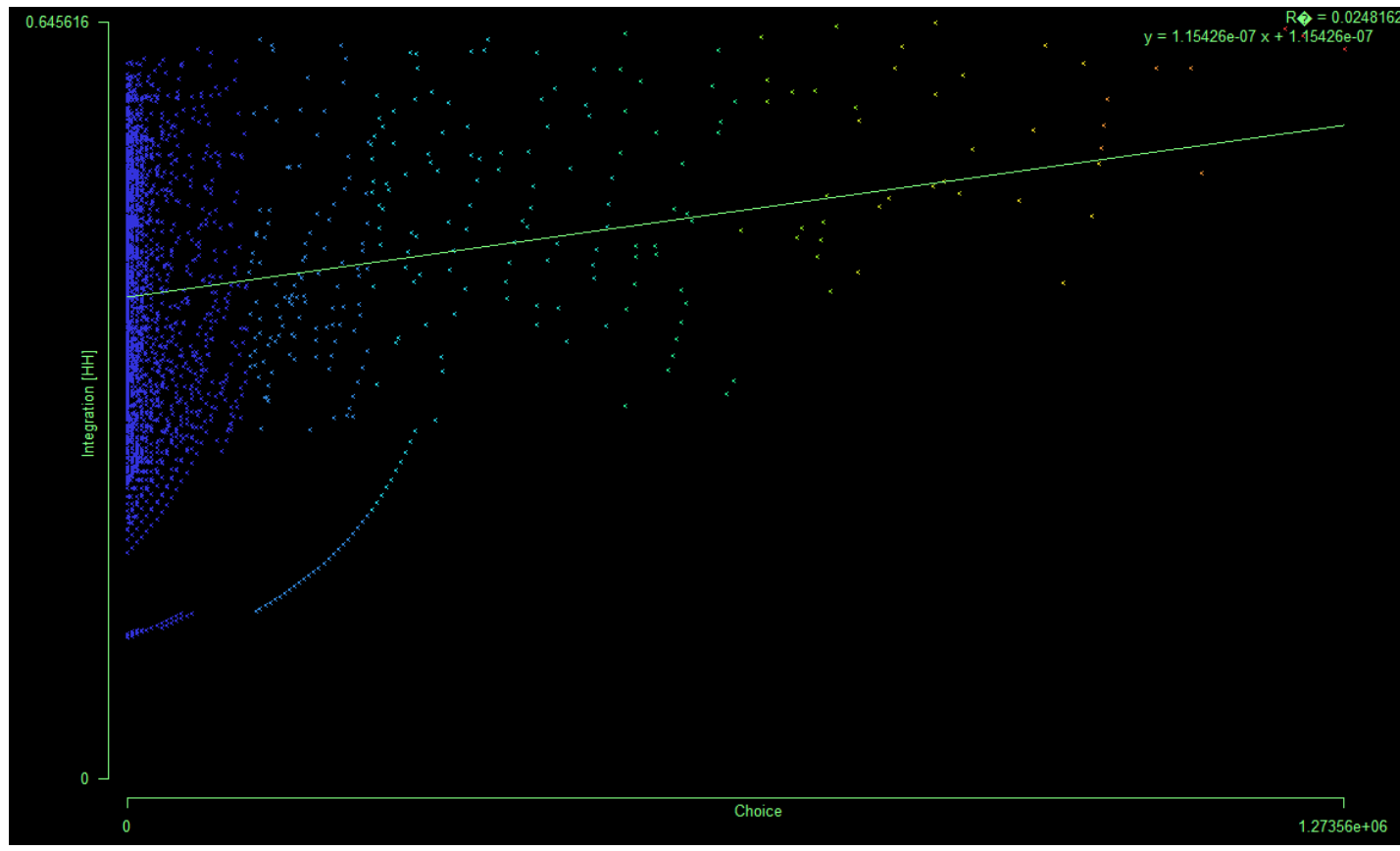

Figure 7. Accessibility: Correlation plot between choice and integration variables.

"urban form" itself. The results construed from the maps of these same variables seem to indicate that the spatial organization is composed by two different urban zones: central and peripheral. The urban areas of expansion are located in the latter. In this context, the results show higher or more positive values of the connectivity and choice variables in the central zone of the urban area than the remaining variables. The fact that the overall integration value is low in the peripheries where there is more urban land area allows us to construe that the value of the control variable is homogeneous in its overall urban space, revealing a symmetrical spatial pattern, while the connections between the roads, which also explain the result of the entropy map, display low values in almost the entire urban area. When matching this data with the social vulnerability map, in which the highest degree of vulnerability can be found in the proximity of the river Frío and the south-western part of the city, we can deduce the fragility to which some communities of citizens may be subjected in a future natural risk scenario, given the proximity to the river. According to the data obtained, both in terms of social structure and urban morphology, it is possible to discuss the degree of social urban spatial structure vulnerability, and to what extent the expansion areas correspond to zones at risk. The results indicate urban peripheries of greater vulnerability in accordance with the social stratum. Similar results can be obtained with the connectivity and Integration data. However, in the inverse case this correlation is lower. The results are inversely related, which may indicate that these expansion areas are not adequately located. The fact that there is a high value of Multidimensional Poverty Index in expansion zones and adjacent to the river Frío allows us to determine that this area is at high risk as far as its socio-spatial vulnerability is concerned. Thus, in the case of any natural climate change incident it will have a direct impact on populations residing in this urban area. Given the data of greater social vulnerability in areas close to the river Frío, this allows us to infer the importance of spatial organization in this case study. Given the results, there is a segregated spatial area near the expansion area of the river. This same space presents a greater social urban risk in the future occurrence of climatic intensity episodes and hence more risk in the face of climate change effects.

\section{Conclusions}

The main research objective was to determine the social urban spatial structure vulnerability in the municipality of Chía, one of the peripheral localities of the Bogotá metropolis. As the new conceptual approach was able to explore the intersection between the social dimension and urban morphology, it can support urban planning processes. Additionally, the conceptual approach proposed would help in the understanding of future impact and adaptation strategies to climate change. The spatial analysis shows the vulnerability of the municipality of Chía based on factors selected for each dimension. Spatial patterns with differentiated behaviours were established to guide decision-makers towards effective and efficient intervention in those sectors where vulnerability is significant.

Patterns of concentration, that is, highs and lows in all variables, were defined, which conform to statistical processes. At the local level, the highest incidence of factors having a direct impact on the Multidimensional Poverty Index is found in sectors in the northern part 
of the municipality in the villages of Fagua, Tíquiza, and Bojacá, in the sector bordering the river Frío. Social and demographic vulnerability is located in certain sectors of the urban area and in some sectors of the hamlets in general.

From the results of the social sphere, it can be concluded that the current areas of urban expansion are in zones of low-level stratification. Therefore, these are areas of high social vulnerability owing to their proximity to the rivers Frío and Bogotá. Regarding the urban morphology dimension, it is possible to deduce a non-standard spatial pattern of contrast between the central and peripheral zones, so that it is possible to state that the existing expansion zones are not evidence of a dubious urban planning strategy because they are in urban areas which are not consolidated in their formal urban structure. From the values obtained in the connectivity and integration maps, it can be concluded that the municipality presents an urban area with a high degree of socio-spatial vulnerability considering the difference between the central and peripheral areas in, respectively, the extreme Northwest and Northeast.

The maps used in this research enable us to conclude that the social urban spatial structure vulnerability degree is higher in expansion areas than in central areas of the city, given that these areas are located adjacent to the river, constituting a high risk for vulnerable urban communities. In this way, a new approach to the location of future urban areas should be considered in the context of adaptation to climate change.

\section{Acknowledgments}

The authors are grateful to the editor of the thematic issue, as well as the reviewers for their important comments and suggestions. The authors wish to express their thanks to the Faculty of Engineering, Universidad de La Sabana, and to the Department of Civil Engineering, Colombian School of Engineering Julio Garavito.

\section{Conflict of Interests}

The authors declare no conflict of interests.

\section{References}

Aguilar, A. G. (2008). Peri-urbanization, illegal settlements and environmental impact in Mexico City. Cities, 25(3), 133-145. https://doi.org/10.1016/ j.cities.2008.02.003

Ahern, J. (1995). Greenways as a planning strategy. Landscape and Urban Planning, 33(1/3), 131-155.

Ahmed, H. A., Singh, S. K., Kumar, M., Maina, M. S., Dzwairo, R., \& Lal, D. (2020). Impact of urbanization and land cover change on urban climate: Case study of Nigeria. Urban Climate, 32, Article 100600. https:// doi.org/10.1016/j.uclim.2020.100600

Alfasi, N., Almagor, J., \& Benenson, I. (2012). The actual impact of comprehensive land-use plans: Insights from high resolution observations. Land Use Policy, 29(4), 862-877.

Ariza-Villaverde, A. B., Jiménez-Hornero, F. J., \& Ravé, E. G. D. (2013). Multifractal analysis of axial maps applied to the study of urban morphology. Computers, Environment and Urban Systems, 38, 1-10. https://doi.org/10.1016/j.compenvurbsys.2012. 11.001

Barros, J. L., Tavares, A. O., Monteiro, M., \& Santos, P. P. (2018). Peri-urbanization and rurbanization in Leiria city: The importance of a planning framework. Sustainability, 10(7), Article 2501.

Basu, T., \& Das, A. (2021). Systematic review of how ecoenvironmental transformation due to urbanization can be investigated in the sustainable development of Indian Cities. Environmental Challenges, 11(22), Article 100099.

Benita, F., \& Piliouras, G. (2020). Location, location, usage: How different notions of centrality can predict land usage in Singapore. Physica A: Statistical Mechanics and Its Applications, 540, Article 123221. https://doi.org/10.1016/j.physa.2019.123221

Bianco, F., \& García-Ayllón, S. (2021). Coastal resilience potential as an indicator of social and morphological vulnerability to beach management. Estuarine, Coastal and Shelf Science, 253, Article 107290. https://doi.org/10.1016/j.ecss.2021.107290

Birkmann, J., Garschagen, M., Kraas, F., \& Quang, N. (2010). Adaptive urban governance: New challenges for the second generation of urban adaptation strategies to climate change. Sustainability Science, 5(2), 185-206. https://doi.org/10.1007/s11625-0100111-3

Brie, M. (2019). Population aging. A demographic vulnerability for the societal security of the European Union. Relaţii Internationale şi Studii Europene, 11, 167-179. https://www.ceeol.com/search/articledetail id $=838980$

Bulkeley, H., \& Tuts, R. (2013). Understanding urban vulnerability, adaptation and resilience in the context of climate change. The International Journal of Justice and Sustainability, 18(6), 646-662. https://doi.org/ 10.1080/13549839.2013.788479

Cámara de Comercio de Bogotá. (2015). Caracterización económica y empresarial de diecinueve municipios de Cundinamarca [Economic and business characterization of nineteen municipalities of Cundinamarca]. https://bibliotecadigital.ccb.org.co/handle/ $11520 / 14584$

Cámara de Comercio de Bogotá, \& Alcaldía de Bogotá. (2015). Somos un territorio metropolitano [We are a metropolitan territory].

Consejo Municipal de Chía. (2016). Acuerdo 100 de 2016 "Por medio del cual se adopta la revisión general y ajustes al plan de ordenamiento territorialPOT-del municipio de Chía, Cundinamarca, adoptado mediante acuerdo 17 de 2000" [Agreement 
100 of 2016 "Through which the general review and adjustments to the land use plan-POT-of the municipality of Chía, Cundinamarca, are adopted, by agreement 17 of 2000].

Contreras Ortíz, Y. (2017). Estado de la vivienda y del espacio público en el municipio de Chía [State of housing and public space in the municipality of Chía]. Universidad Nacional de Colombia, Instituto de Estudios Urbanos.

D'Acci, L. (2019). Orientational versus esthetical urban street morphology parameterization in space syntax. Spatial Cognition \& Computation, 19(3), 172-189.

Dadashpoor, H., \& Ahani, S. (2021). Explaining objective forces, driving forces, and causal mechanisms affecting the formation and expansion of the periurban areas: A critical realism approach. Land Use Policy, 102, Article 105232. https://doi.org/10.1016/ j.landusepol.2020.105232

de Espindola, G. M., da Costa Carneiro, E. L. N., \& Façanha, A. C. (2017). Four decades of urban sprawl and population growth in Teresina, Brazil. Applied Geography, 79, 73-83.

de Oliveira Lemos, L., Oscar Júnior, A. C., \& de Assis Mendonça, F. (2021). Urban climate maps as a public health tool for urban planning: The case of dengue fever in Rio De Janeiro/Brazil. Urban Climate, 35, Article 100749. https://doi.org/10.1016/j.uclim. 2020.100749

Department of National Planning. (2017). Panorámica regional. Pobreza monetaria y multidimensional departamental: Necesidad de politicas públicas diferenciadas [Monetary and multidimensional departmental poverty: The need for differentiated public policies]. https://colaboracion.dnp.gov.co/ CDT/Desarrollo\%20Territorial/Portal\%20Territorial/ KitSeguimiento/Pobreza/Publicaci\%C3\%B3n\% 20lpm\%20deptal.pdf

Dou, K., \& Zhan, Q. (2011, June 24-26). Accessibility analysis of urban emergency shelters: Comparing gravity model and space syntax [Paper presentation]. 2011 International Conference on Remote Sensing, Environment and Transportation Engineering, Nanjing, China.

Du, M., Zhang, X., Wang, Y., Tao, L., \& Li, H. (2020). An operationalizing model for measuring urban resilience on land expansion. Habitat International, 102, Article 102206. https://doi.org/10.1016/ j.habitatint.2020.102206

Duran Giraldo, C., \& Suárez Jaraba, M. A. (2013). Gestión ambiental de las zonas afectadas por inundaciones en el municipio de Chía [Environmental management of the areas affected by floods in the municipality of Chía] [Master's thesis, Pontificia Universidad Javeriana]. https://repository.javeriana.edu.co/bitstream/ handle/10554/13507/DuranGiraldoCarolina2013. pdf?sequence $=1$

Eakin, H., \& Luers, A. (2006). Assessing the vulnerability of social environmental systems. Annual
Review of Environment and Resources, 31, 365-394. https://doi.org/10.1146/annurev.energy.30.050504. 144352

Gan, L., Shi, H., Hu, Y., Lev, B., \& Lan, H. (2020). Coupling coordination degree for urbanization city-industry integration level: Sichuan case. Sustainable Cities and Society, 58, Article 102136.

Gencer, E. A. (2013). Natural disasters, urban vulnerability, and risk management: A theoretical overview. In E. A. Gencer (Ed.), The interplay between urban development, vulnerability, and risk management: A case study of the Istanbul metropolitan area (pp. 7-43). Springer. https://doi.org/10.1007/978-3-64229470-9_2

Ghosh, S., \& Das, A. (2019). Urban expansion induced vulnerability assessment of East Kolkata Wetland using fuzzy MCDM method. Remote Sensing Applications: Society and Environment, 13, 191-203. https://doi. org/10.1016/j.rsase.2018.10.014

Giordano, R., Pilli-Sihvola, K., Pluchinotta, I., Matarrese, R., \& Perrels, A. (2020). Urban adaptation to climate change: Climate services for supporting collaborative planning. Climate Services, 17, Article 100100. https://doi.org/10.1016/j.cliser.2019.04.004

Gonzales, L. P., \& Magnaye, D. C. (2017). Measuring the urban biodiversity of green spaces in a highly urbanizing environment and its implications for human settlement resiliency planning: The case of Manila City, Philippines. Procedia Environmental Sciences, 37, 83-100.

Guevara, S. J. D., \& Shields, R. (2019). Spatializing stratification: Bogotá. Ardeth, 2019(4), 223-236. http:// journals.openedition.org/ardeth/544

Guo, Z., Hu, Y., \& Zheng, X. (2020). Evaluating the effectiveness of land use master plans in built-up land management: A case study of the Jinan municipality, eastern China. Land Use Policy, 91, Article 104369.

Hersperger, A. M., Oliveira, E., Pagliarin, S., Palka, G., Verburg, P., Bolliger, J., \& Grădinaru, S. (2018). Urban land-use change: The role of strategic spatial planning. Global Environmental Change, 51, 32-42.

Hill, K. (2016). Climate change: Implications for the assumptions, goals and methods of urban environmental planning. Urban Planning, 1(4), 103-113.

Hillier, B., \& Hanson, J. (1989). The social logic of space. Cambridge University Press.

Hogan, D. J., \& Marandola, E., Jr. (2005). Towards an interdisciplinary conceptualisation of vulnerability. Population Space and Place, 11(6), 455-471. https://doi. org/10.1002/psp.401

Inostroza, L., Baur, R., \& Csaplovics, E. (2013). Urban sprawl and fragmentation in Latin America: A dynamic quantification and characterization of spatial patterns. Journal of Environmental Management, 115, 87-97.

Intergovernmental Panel on Climate Change. (2007). Climate change 2007: Impacts, adaptation and vulnerability. https://www.ipcc.ch/site/assets/uploads/ 
2018/03/ar4_wg2_full_report.pdf

Jaeger, J. A., Bertiller, R., Schwick, C., \& Kienast, F. (2010). Suitability criteria for measures of urban sprawl. Ecological Indicators, 10(2), 397-406.

Jayasinghe, A., Sano, K., Abenayake, C. C., \& Mahanama, P. K. S. (2019). A novel approach to model traffic on road segments of large-scale urban road networks. MethodsX, 6, 1147-1163. https://doi.org/10.1016/ j.mex.2019.04.024

Jimenez Aguilar, C. M., \& Thoene, U. (2021). Associativity in the Bogotá metropolitan region: Coordination challenges in a fragmented region. Area Development and Policy, 6(4), 451-469. https://doi.org/10.1080/ 23792949.2020.1848441

Lee, S., \& Kim, Y. (2021). A framework of biophilic urbanism for improving climate change adaptability in urban environments. Urban Forestry \& Urban Greening, 61, Article 127104. https://doi.org/10.1016/ j.ufug.2021.127104

Li, Y., Zhang, X., Zhao, X., Ma, S., Cao, H., \& Cao, J. (2016). Assessing spatial vulnerability from rapid urbanization to inform coastal urban regional planning. Ocean \& Coastal Management, 123, 53-65.

Liu, M., \& Lo, K. (2021). Governing eco-cities in China: Urban climate experimentation, international cooperation, and multilevel governance. Geoforum, 121, 12-22. https://doi.org/10.1016/j.geoforum.2021.02. 017

Liu, N., \& Morawska, L. (2020). Modeling the urban heat island mitigation effect of cool coatings in realistic urban morphology. Journal of Cleaner Production, 264, Article 121560. https://doi.org/10.1016/ j.jclepro.2020.121560

Liu, X., Wu, J., Huang, J., Zhang, J., Chen, B. Y., \& Chen, A. (2021). Spatial-interaction network analysis of built environmental influence on daily public transport demand. Journal of Transport Geography, 92, Article 102991. https://doi.org/10.1016/j.jtrangeo.2021. 102991

Madlener, R., \& Sunak, Y. (2011). Impacts of urbanization on urban structures and energy demand: What can we learn for urban energy planning and urbanization management? Sustainable Cities and Society, 1(1), 45-53.

Matsa, M., Mupepi, O., \& Musasa, T. (2021). Spatiotemporal analysis of urban area expansion in Zimbabwe between 1990 and 2020: The case of Gweru city. Environmental Challenges, 4, Article 100141. https://doi.org/10.1016/j.envc.2021.100141

Menzori, I. D., Sousa, I. C. N. d., \& Gonçalves, L. M. (2021). Urban growth management and territorial governance approaches: A master plans conformance analysis. Land Use Policy, 105, Article 105436. https:// doi.org/10.1016/j.landusepol.2021.105436

Morales, J., Flacke, J., Morales, J., \& Zevenbergen, J. (2019). Mapping urban accessibility in data scarce contexts using space syntax and location-based methods. Applied Spatial Analysis and Policy, 12(2),
205-228.

National Administrative Department of Statistics of Colombia. (2021a). Estratificación socioeconómica: Preguntas frecuentes [Socioeconomic stratification: Frequently asked questions]. https://www.dane. gov.co/index.php/116-espanol/informaciongeorreferenciada/2421-estratificacionsocioeconomica-preguntas-frecuentes

National Administrative Department of Statistics of Colombia. (2021b). Visor de vulnerabilidad [Vulnerability viewer]. http://visor01.dane.gov.co/visorvulnerabilidad

Nigro, A., Bertolini, L., \& Moccia, F. D. (2019). Land use and public transport integration in small cities and towns: Assessment methodology and application. Journal of Transport Geography, 74, 110-124. https://doi.org/10.1016/j.jtrangeo.2018.11.004

Osorio Ardila, G. (2012). Aspectos culturales de la segregación residencial. Barrios cerrados en el área rural de Chía [Cultural aspects of residential segregation. Closed neighborhoods in the rural area of Chía]. Ciudad Paz-ando, 5(1), 49-64. https://revistas.udistrital. edu.co/index.php/cpaz/article/view/7275

Otto, I. M., Reckien, D., Reyer, C. P. O., Marcus, R., Le Masson, V., Jones, L., Norton, A., \& Serdeczny, O. (2017). Social vulnerability to climate change: A review of concepts and evidence. Regional Environmental Change, 17(6), 1651-1662. https://doi.org/ 10.1007/s10113-017-1105-9

Ouyang, X., Wei, X., Li, Y., Wang, X.-C., \& Klemeš, J. J. (2021). Impacts of urban land morphology on PM2: 5 concentration in the urban agglomerations of China. Journal of Environmental Management, 283, Article 112000.

Padeiro, M. (2016). Conformance in land-use planning: The determinants of decision, conversion and transgression. Land Use Policy, 55, 285-299.

Penn, A. (2003). Space syntax and spatial cognition or why the axial line? Environment and Behavior, 35(1), 30-65.

Qi, J., Ding, L., \& Lim, S. (2020). Ontology-based knowledge representation of urban heat island mitigation strategies. Sustainable Cities and Society, 52, Article 101875. https://doi.org/10.1016/j.scs.2019.101875

R Core Team. (2021). The R project for statistical computing. https://www.R-project.org

Rani, W., Kamarudin, K., Razak, K., \& Asmawi, Z. (2020). Climate change adaptation and disaster risk reduction in urban development plans for resilient cities. IOP Conference Series: Earth and Environmental Science, 409, Article 012024. https://doi.org/10.1088/ 1755-1315/409/1/012024

Remali, A. M., Porta, S., Romice, O., Abudib, H., \& Vaughan, L. (2015). Street quality, street life, street centrality. In L. Vaughan (Ed.), Suburban urbanities: Suburbs and the life of the high street (pp. 104-129). UCL Press.

Rodríguez Domenech, M. A. (2016). Vulnerabilidad 
demográfica en las regiones europeas NUTS-2. El caso de Castilla-La Mancha [Demographic vulnerability in the European regions NUTs-2. The case of Castilla-La Mancha]. Papeles de Población, 22(89), 165-200. https://dialnet.unirioja.es/ejemplar/ 449373

Romero Lankao, P., \& Qin, H. (2011). Conceptualizing urban vulnerability to global climate and environmental change. Sustainability, 3(3), 142-149. https:// doi.org/10.1016/j.cosust.2010.12.016

Salimi, M., \& Al-Ghamdi, S. G. (2020). Climate change impacts on critical urban infrastructure and urban resiliency strategies for the Middle East. Sustainable Cities and Society, 54, Article 101948. https://doi. org/10.1016/j.scs.2019.101948

Santos, M. M., Lanzinha, J. C. G., \& Ferreira, A. V. (2021). Review on urbanism and climate change. Cities, 114, Article 103176. https://doi.org/10.1016/ j.cities.2021.103176

Sharifi, A. (2021). Co-benefits and synergies between urban climate change mitigation and adaptation measures: A literature review. Science of the Total Environment, 750, Article 141642. https://doi.org/ 10.1016/j.scitotenv.2020.141642

Shen, X., Wang, X., Zhang, Z., Lu, Z., \& Lv, T. (2019). Evaluating the effectiveness of land use plans in containing urban expansion: An integrated view. Land Use Policy, 80, 205-213.

Turner, A. (2007). From axial to road-centre lines: A new representation for space syntax and a new model of route choice for transport network analysis. Environment and Planning B: Planning and Design, 34(3), 539-555.

Unceta, P. M., Hausleitner, B., \& Dąbrowski, M. (2020). Socio-spatial segregation and the spatial structure of 'ordinary' activities in the Global South. Urban Planning, 5(3), 303-318.

Weldearegay, S. K., Tefera, M. M., \& Feleke, S. T. (2021). Impact of urban expansion to peri-urban smallholder farmers' poverty in Tigray, North Ethiopia. Heliyon, 7(6), e07303. https://doi.org/10.1016/ j.heliyon.2021.e07303

While, A., \& Whitehead, M. (2013). Cities, urbanisation and climate change. Urban Studies, 50(7), 1325-1331. https://doi.org/10.1177/004209801348 0963

Yamu, C., van Nes, A., \& Garau, C. (2021). Bill Hillier's legacy: Space syntax-A synopsis of basic concepts, measures, and empirical application. Sustainability, 13(6), Article 3394.

Yan, Y., Wu, C., \& Wen, Y. (2021). Determining the impacts of climate change and urban expansion on net primary productivity using the spatio-temporal fusion of remote sensing data. Ecological Indicators, 127, Article 107737. https://doi.org/10.1016/ j.ecolind.2021.107737

Ye, B., Jiang, J., Liu, J., Zheng, Y., \& Zhou, N. (2021). Research on quantitative assessment of climate change risk at an urban scale: Review of recent progress and outlook of future direction. Renewable and Sustainable Energy Reviews, 135, Article 110415. https://doi.org/10.1016/j.rser.2020.110415

Zhang, J., Yu, Z., Cheng, Y., Chen, C., Wan, Y., Zhao, B., \& Vejre, H. (2020). Evaluating the disparities in urban green space provision in communities with diverse built environments: The case of a rapidly urbanizing Chinese city. Building and Environment, 183, Article 107170. https://doi.org/10.1016/j.buildenv. 2020.107170

\section{About the Authors}
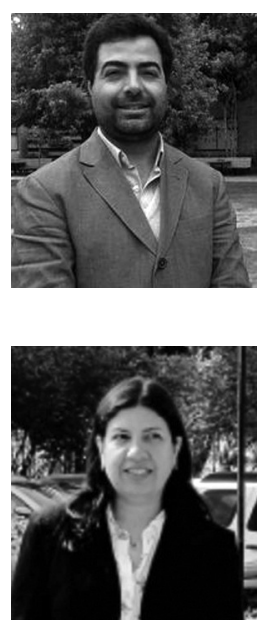

Vasco Barbosa is associate professor at Universidad de La Sabana, Colombia, and an expert member at the European Science Foundation and the European Commission. He was a post-doctorate in urban planning at the University of Trás-os-Montes e Alto Douro, Portugal, and the Federal University of Viçosa, Brazil (2014-2018). He has a PhD in territorial planning and rural development (2013) and an MSc in management and planning of sustainable land use (2011) from the University of Santiago de Compostela, Spain. He is also an architect who graduated from the Faculty of Architecture and Arts, Lusíada University, Porto, Portugal, in 2000.

Mónica Marcela Suárez Pradilla is a full-time assistant professor at the Roads and Transportation Center of the Civil Engineering Department of the Colombian School of Engineering Julio Garavito (Bogotá, Colombia). As a teacher and researcher, her areas of interest are sustainable urban transport, urban and territorial development, and the effects of infrastructure and transport systems on the territory. 